\title{
Cattle production in the Amazon Rainforest: reasons for the success, challenges for ecological intensification
}

\author{
Poccard-Chapuis René ${ }^{1 \dagger}$, Ferreira Laura ${ }^{2}$, Nahum Benjamin ${ }^{2}$, Carvalho Soraya $^{2}$ and Tourrand \\ Jean-François ${ }^{1}$
}

${ }^{1}$ IRAD, Embrapa Amazonia Oriental, 66095-100 Belém, Brazil; ${ }^{2}$ Université Fédérale du Pará, Brazil

The current expansion of cattle ranching in the Amazon, especially in its Brazilian part, is responsible for a major change in the global livestock geography. Brazil is the leading bovine meat producer and exporter in the world, with a population of 202 million heads in 2008 . The Amazon region accounts for nearly 80 million heads, and has the strongest growth rate, being associated with a strong meat and milk industry. This success of the cattle ranching activity has been hidden for a long time by the scientific community. It is now one of the major challenges of sustainable development on the continent.

This communication is based on the results of several research projects from the Transamazônia network, analyzing: production systems, commodity chains and territorial development strategies, with several methods, most of them based on systemic approaches. The paper discusses three mechanisms, explaining the impacts of livestock production on the Amazon Environment, and concludes on challenges for the research around the concept of ecological intensification.

The results show that the Amazonian farmers have been able, over 40 years of colonization, to build livestock systems relatively adapted to the agro-ecological conditions of the humid tropics, and to the specific contexts of the agrarian frontier. Differently than other agricultural activities in this region, the cattle ranching systems are based on flexible and efficient technical and economical systems, both at the farm or the commodity chain scale. Cattle ranching activities are now integrated in most of the production systems on the pioneer frontier, with many functions that stand beyond the sole production of income. Public policies and agricultural research has been decisive for starting this process, which is now controlled by a diversified private sector (including the large agro-business companies, and the settlers of agricultural reform). However, the Amazonian livestock system development remains very harmful in terms of environmental impact, including the associated fast deforestation process. This great expansion is responsible for the loss of biodiversity and therefore has this responsibility along with the impact on climate change, at global and local scales.

The results of these research programs indicate three dimensions of livestock production impacts on the Amazon environment. One is about the farmers land tenure strategies: one function of livestock activities is the struggle for land. The Amazon farmers are pioneers, building new frontier regions, in critical economic, social, political and logistical contexts. The easier way to build an economical capital is land accumulation, and grasslands are the best way for land appropriation, at the expense of the forest. The second is the extensive practice of pasture management. The results show low technical efficiency of these practices, in terms of animal production. Soil fertility management, forage productivity, pasture maintenance, grazing management should progress and improve land productivity. The demand for land, especially for small farmers, should decrease. The third is landscape reconstruction. Four decades of systematic deforestation have built a new landscape, composed of huge areas without forests or trees: the ecological impact is maximum, especially for the local water cycle and animal biodiversity. Silvopastoralism, respecting the Permanent Protected Areas (riparian forest, relief), is the basis for building an "eco-efficient" landscape.

Amazon deforestation is now decreasing, thanks to new public policies and marketing chain organizations. But to promote a positive impact of livestock on the Amazon environment, local actors have to build innovative processes, based on existing technologies, institutional arrangements especially at the local scale, and monitoring tools.

The challenges for research are to elaborate these innovative processes, aiming at better integrating the production systems inside the Amazonian ecosystems, and increasing their productive and ecological efficiencies. Integrations between agriculture, livestock and forestry, at the farm scale and, mostly, at the territory scale, are a good way to optimize the nutrient cycles. Beyond the necessary local partnerships, this requires gaining knowledge and improved information flows on GHG emissions in the different systems and carbon sequestration or avoided emission capabilities according to different management practices, but also to contribute building new livestock policies and adapted regulations, at both the scales of local institutions, national government or agencies, and commodity chains. REDD ++ mechanisms should be useful, in this context only.

\footnotetext{
†E-mail: renepoccard@gmail.com
} 